\title{
Terpenoid Derivatives as Potential Trypanocidal Agents
}

\author{
Lozano $E^{1}$, Barrera $\mathbf{P}^{1,2}$, Spina $\mathbf{R}^{1}$ and Sosa MA $^{1,2 *}$ \\ ${ }^{1}$ Instituto de Histología y Embriología, Facultad de Ciencias Médicas, UNCuyo, Mendoza, Argentina \\ ${ }^{2}$ Facultad de Ciencias Exactas y Naturales, UNCuyo, Mendoza, Argentina
}

\begin{abstract}
In this review we refer to a promising family of molecules in the fight against Chagas disease. Terpene derivatives are abundant in the plant Kingdom and in the last years many compounds have shown important biological activities. Diterpenes and sesquiterpene lactones have shown in vitro and in vivo trypanocidal activity and they emerge as potential antichagasic drugs. These molecules may act on these parasites by multiple mechanisms, as it has been reported. Moreover, given the chemical structure of these compounds it is feasible to modify these molecules by chemical substitution in order to optimize their action against parasites.
\end{abstract}

Keywords: Chagas disease; Trypanosoma cruzi; Mammalian cells; Trypanocidal activity

\section{Chagas Disease}

Chagas disease or American trypanosomiasis is a disease caused by the kinetoplastid protozoan Trypanosoma cruzi. This parasitic disease affects millions of people in Latin America and is still expanding worldwide due to migration phenomena. Chagas is one of the most devastating diseases caused by parasites of the Trypanosomatidae family. Trypanosoma cruzi is transmitted through the bite of triatiomine haematophage insects such as Triatoma infestans. However, congenital and transfusion (iatrogenic) transmission are also relevant in the transmission cycle, since they are responsible for the expansion of this disease in non-endemic areas [1]. After an acute phase and subsequent state of latency, the disease commonly progresses to a chronic phase, with clinical manifestations in various organs. The chronic manifestations of the disease are sometimes life-threatening [2-4]. Although advances have been made in the field of molecular biology and pathophysiology of Chagas disease, the search for an effective treatment has yet been unsuccessful due to several reasons; a) the existence of a wide variety of strains, with different virulence and drug resistance profile, b) the fact that the acute phase is often asymptomatic, c) the difficulty to find a drug with suitable selectivity for the parasite, and d) most funds are intended for the development of diagnostic tests and prevention.

For decades, the search for drugs to treat Chagas disease has been a constant challenge. Nowadays, the treatments of Chagas' disease entail the election between either one of two nitroheterocyclic compounds, that is, benznidazole or nifurtimox [5-7]. Both drugs are effective when administered at the onset of the acute phase. Conversely, their effectiveness is limited during the chronic stage, there are regional degrees of effectiveness due to drug resistance; and they present severe side effects that lead to the immediate interruption of treatment in a high percentage of the patients. Most of the knowledge that currently exists about the biology of the parasite and the identification of potential molecular targets, together with the wide range of natural molecules, mainly in the plant kingdom, has encouraged researchers to continue the intense search for new drugs against T. cruzi [8-10]. The main vulnerability of parasites is related to the high sensitivity to oxidative stress due to the rudimentary defense system they have $[11,12]$. Natural compounds are an attractive source of new drugs, because they can be subjected to synthetic modifications to optimize their bioactivity. Thus, families of natural compounds have been tested as potential trypanocidal agents in in vitro and in vivo assays $[13,14]$. Although many compounds that have been tested have shown strong trypanocidal activity in vitro, few of them have been tested in clinical trials for the treatment of Chagas disease [15,16]. More recently, terpenes and sesquiterpene lactones obtained from the plant leaves have shown high toxicity on the different stages of parasites and with low toxicity on mammalian cells $[17,18]$. Terpene derivatives are very abundant in nature, therefore, they are an attractive compounds family to be assayed for biological activity. Over the past ten years, hundreds of new terpene-derived molecules exhibiting trypanocidal activity have been described [19-27] and some of them have already been tested against T. cruzi both in vitro and in vivo [28,29]. Interestingly, some of these molecules are feasible to modify chemically in order to optimize their action on parasites. For example, an increase of lipophilicity by chemical modifications has proved to be an adequate strategy for improving the trypanocidal activity of diterpenes (Figure 1) [23,30,31].

Other terpenoid derivatives such as sesquiterpene lactones are known to have a wide spectrum of biological activities, mostly mediated through $\alpha, \beta$-unsaturated carbonyl groups [32,33]. Many sesquiterpene lactones with high activity against $T$. cruzi have been isolated from the aerial parts of plants [34-36]. The mechanism of action of some sesquiterpene lactones is currently under study. In some cases, it has been reported that these compounds can generate free radicals within trypanosomes [37,38]. Accordingly, ultrastructural studies have demonstrated that most of these compounds may affect mitochondrial function $[39,40]$. It is known that de $\alpha$-methylene- $\gamma$ lactone of sesquiterpene lactones is responsible for most of the biological

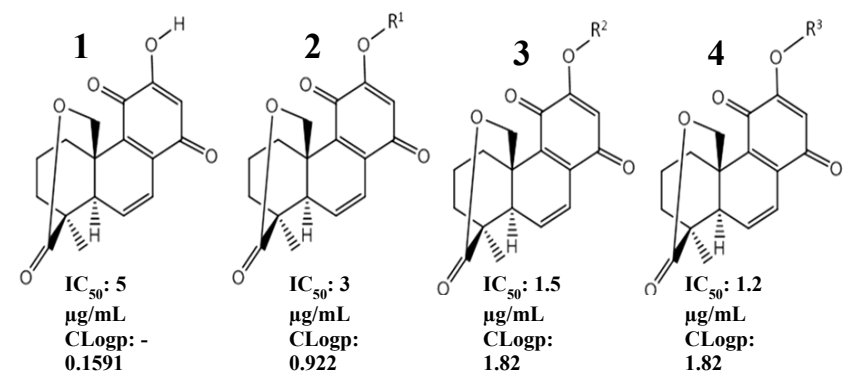

Figure 1: Structures of Abietane (1), and three derivatives (2-4). $\mathrm{R}^{1}: \mathrm{COCH}_{3}$ $\mathrm{R}^{2}$ : $\mathrm{Si}\left(\mathrm{CH}_{3}\right)_{3}$ and $\mathrm{R}^{3}: \mathrm{CH}_{2}-\mathrm{CH}=\mathrm{CH}_{2}(30)$.

*Corresponding author: Miguel A. Sosa, Instituto de Histología y Embriología, FCMUNCuyo, Mendoza, Argentina, Tel: +542614135000; E-mail: msosa@fcm.uncu.edu.ar Received April 28, 2016; Accepted May 05, 2016; Published May 10, 2016

Citation: Lozano E, Barrera P, Spina R, Sosa MA (2016) Terpenoid Derivatives as Potential Trypanocidal Agents. Med chem (Los Angeles) 6: 319-321. doi:10.4172/2161-0444.1000363

Copyright: (c) 2016 Lozano E, et al. This is an open-access article distributed under the terms of the Creative Commons Attribution License, which permits unrestricted use, distribution, and reproduction in any medium, provided the original author and source are credited. 


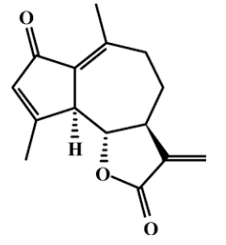

Dehydroleucodine

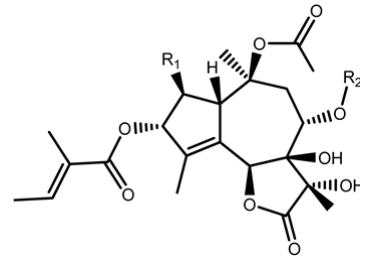

Thapsigargin
Figure 2: Structure Dehydroleucodine and Thapsigargin.

properties of these compounds [41]. Some authors have suggested that the cytotoxicity of these compounds is mediated by an interaction of the $a$-methylene with sulphydryl groups of enzymes that are crucial for parasite life survival [42]. It is also possible that these compounds may affect calcium metabolism, given their similarity to thapsigargin, a potent inhibitor of this ion (Figure 2). The latter hypothesis has not yet been tested.

All these studies along with others that have been carried out since the 50 s $[43,44]$ have contributed to the understanding of the life cycle of parasites and to clarify some molecular targets that could be used for the development of drugs against T. cruzi.

\section{References}

1. Kemmerling U, Bosco C, Galanti N (2010) Infection and invasion mechanisms of Trypanosoma cruzi in the congenital transmission of Chagas' disease: a proposal. Biol Res 43: 307-316.

2. Andrade DV, Gollob KJ, Dutra WO (2014) Acute chagas disease: new global challenges for an old neglected disease. PLoS Negl Trop Dis 8: e3010.

3. World Health Organization (2015) Tropical Disease Research, Program for research and training tropical disease (TDR), Fact sheet Nu 340.

4. Ferreira LG, de Oliveira MT, Andricopulo AD (2016) Advances and Progress in Chagas Disease Drug Discovery. Curr Top Med Chem.

5. Rodriguez-Guerineau L, Posfay-Barbe KM, Monsonis-Cabedo M, JuncosaMorros T, Diana A, et al. (2014) Pediatric Chagas disease in Europe: 45 cases from Spain and Switzerland. Pediatr Infect Dis J 33: 458-462.

6. Viotti R, Alarcón de NB, Araujo-Jorge T, Grijalva MJ, Guhl F, et al. (2014) Latin American Network for Chagas Disease, NHEPACHA. Towards a paradigm shift in the treatment of chronic Chagas disease. Antimicrob Agents Chemother 58: 635-639.

7. Salomão K, Menna-Barreto RF, de Castro SL (2016) Stairway to heaven or hell? Perspectives and limitations of Chagas disease chemotherapy. Curr Top Med Chem.

8. Izumi E, Ueda-Nakamura T, Dias Filho BP, Veiga Júnior VF, Nakamura CV (2011) Natural products and Chagas' disease: a review of plant compounds studied for activity against Trypanosoma cruzi. Nat Prod Rep 28 809-823.

9. Farimani MM, Taheri S, Ebrahimi SN, Bahadori MB, Khavasi HR, et al. (2012) Hydrangenone, a new isoprenoid with an unprecedented skeleton from Salvia hydrangea. Org Lett 14: 166-169.

10. Swinney DC (2013) Phenotypic vs. target-based drug discovery for first-inclass medicines. Clin Pharmacol Ther 93: 299-301.

11. Müller M, Mascher H, Kikuta C, Schäfer S, Brunner M, et al. (1997) Diclofenac concentrations in defined tissue layers after topical adminstration. Clin Pharmacol Ther 60: 293-299.

12. Lazarin-Bidóia D, Desoti VC, Martins SC, Ribeiro FM, Ud Din Z, et al. (2015) Dibenzylideneacetones Are Potent Trypanocidal Compounds That Affect the Trypanosoma cruzi Redox System. Antimicrob Agents Chemother 60: 890-903.

13. Machado-Silva A, Cerqueira PG, Grazielle-Silva V, Gadelha FR, Peloso Ede F, et al. (2016) How Trypanosoma cruzi deals with oxidative stress: Antioxidant defence and DNA repair pathways. Mutat Res Rev Mutat Res 767: 8-22.

14. Dias DA, Urban S, Roessner U (2012) A historical overview of natural products in drug discovery. Metabolites 2: 303-336.

15. Sandjo LP, de Moraes MH, Kuete V, Kamdoumd BC, Ngadjui BT, et al. (2016)
Individual and combined antiparasitic effect of six plant metabolites against Leishmania amazonensis and Trypanosoma cruzi. Bioorg Med Chem Lett 26: 1772-1775.

16. Bahia MT, de Andrade IM, Martins TA, do Nascimento ÁF, Diniz Lde F, et al (2012) Fexinidazole: a potential new drug candidate for Chagas disease. PLoS Negl Trop Dis 6: e1870.

17. Urbina JA (2009) Ergosterol biosynthesis and drug development for Chagas disease. Mem Inst Oswaldo Cruz 104 Suppl 1: 311-318.

18. Sülsen VP, Frank FM, Cazorla SI, Barrera P, Freixa B, et al. (2011) Psilostachyin C: a natural compound with trypanocidal activity. Int J Antimicrob Agents 37: 536-543.

19. Lozano E, Barrera P, Tonn C, Nieto M, Sartor T, et al. (2012) The effect of the diterpene 5-epi-icetexone on the cell cycle of Trypanosoma cruzi. Parasitol Int 61: $275-279$.

20. Schmidt TJ, Kaiser M, Brun R (2011) Complete structural assignment of serratol, a cembrane-type diterpene from Boswellia serrata, and evaluation of its antiprotozoal activity. Planta Med 77: 849-850.

21. Ramírez-Macías I, Marín C, Es-Samti H, Fernández A, Guardia JJ, et al. (2012) Taiwaniaquinoid and abietane quinone derivatives with trypanocidal activity against T. cruzi and Leishmania spp. Parasitol Int 61: 405-413.

22. Lozano E, Barrera P, Salinas R, Vega I, Nieto M, et al. (2012) Sesquiterpene lactones and the diterpene 5-epi-icetexone affect the intracellular and extracellular stages of Trypanosoma cruzi. Parasitol Int 61: 628-633.

23. Izumi E, Ueda-Nakamura T, Veiga VF Jr, Pinto AC, Nakamura CV (2012) Terpenes from Copaifera demonstrated in vitro antiparasitic and synergic activity. J Med Chem 55: 2994-3001.

24. Varela J, Serna E, Torres S, Yaluff G, de Bilbao NI, et al. (2014) In vivo antiTrypanosoma cruzi activity of hydro-ethanolic extract and isolated active principles from Aristeguietia glutinosa and mechanism of action studies. Molecules 19: 8488-8502.

25. Siless GE, Lozano E, Sánchez M, Mazzuca M, Sosa MA, et al. (2013) Preparation and antitrypanosomal activity of secochiliolide acid derivatives. Bioorg Med Chem Lett 23: 4964-4967.

26. Jansen DJ, Shenvi RA (2014) Synthesis of medicinally relevant terpenes: reducing the cost and time of drug discovery. Future Med Chem 6: 1127-1148.

27. Thao NP, Luyen BT, Brun R, et al. (2015) Anti-Protozoal Activities of CembraneType Diterpenes from Vietnamese Soft Corals. Molecules 20: 12459-12468.

28. Suto Y, Nakajima-Shimada J, Yamagiwa N, Onizuka Y, Iwasaki G (2015) Synthesis and biological evaluation of quinones derived from natural product komaroviquinone as anti-Trypanosoma cruzi agents. Bioorg Med Chem Lett 25: 2967-2971.

29. Sülsen VP, Cazorla SI, Frank FM, Laurella LC, Muschietti LV, et al. (2013) Natural terpenoids from Ambrosia species are active in vitro and in vivo against human pathogenic trypanosomatids. PLoS Negl Trop Dis 7: e2494.

30. Lozano E, Strauss M, Spina R, Cifuente D, Tonn C, et al. (2016) The in vivo trypanocidal effect of the diterpene 5-epi-icetexone obtained from Salvia gilliesii. Parasitol Int 65: 23-26.

31. Lozano ES, Spina RM, Tonn CE, Sosa MA, Cifuente DA (2015) An abietane diterpene from Salvia cuspidata and some new derivatives are active against Trypanosoma cruzi. Bioorg Med Chem Lett 25: 5481-5484.

32. Olmo F, Guardia JJ, Marin C, Messouri I, Rosales MJ, et al. (2015) Prospects of an alternative treatment against Trypanosoma cruzi based on abietic acid derivatives show promising results in Balb/c mouse model. Eur J Med Chem 89: 683-690.

33. Picman AK (1986) Biological activities of sesquiterpene lactones. Biochem Syst Ecol 14: 255-281.

34. Schmidt TJ (1999) Toxic activities of sesquiterpene lactones-structural and biochemical aspects. Current Org Chem 3: 577-605.

35. Schmidt TJ, Brun R, Willuhn G, Khalid SA (2002) Anti-trypanosomal activity of helenalin and some structurally related sesquiterpene lactones. Planta Med 68: $750-751$.

36. Fabian L, Sulsen V, Frank F, Cazorla S, Malchiodi E, et al. (2013) In silico study of structural and geometrical requirements of natural sesquiterpene lactones with trypanocidal activity. Mini Rev Med Chem 13: 1407-1414.

37. Jimenez-Ortiz V, Brengio SD, Giordano O, Tonn C, Sánchez M, et al. (2005) 
Citation: Lozano E, Barrera P, Spina R, Sosa MA (2016) Terpenoid Derivatives as Potential Trypanocidal Agents. Med chem (Los Angeles) 6: 319321. doi:10.4172/2161-0444.1000363

The trypanocidal effect of sesquiterpene lactones helenalin and mexicanin on cultured epimastigotes. J Parasitol 91: 170-174.

38. Gach K, Dlugosz A, Janecka A (2015) The role of oxidative stress in anticancer activity of sesquiterpene lactones. Naunyn Schmiedebergs Arch Pharmacol 388: $477-486$

39. Sülsen VP, Puente V, Papademetrio D, Batlle A, Martino VS, et al. (2016) Mode of Action of the Sesquiterpene Lactones Psilostachyin and Psilostachyin C on Trypanosoma cruzi. PLoS One 11: e0150526.

40. Barrera P, Jimenez-Ortiz V, Giordano O, Tonn C, Galanti N, et al. (2008) Natural sesquiterpene lactones are active against Leishmania mexicana possible by multiple effects. J Parasitol 94: 1143-1149.
41. Sülsen V, Barrera P, Muschietti L, Martino V, Sosa M (2010) Antiproliferative effect and ultrastructural alterations induced by psilostachyin on Trypanosoma cruzi. Molecules 15: 545-553.

42. Giordano OS, Guerreiro E, Pestchanker MJ, Guzman J, Pastor D, et al. (1990) The gastric cytoprotective effect of several sesquiterpene lactones. J Nat Prod 53: 803-809.

43. Hwang D, Fischer NH, Jang BC, Tak H, Kim JK, et al. (1996) Inhibition of the expression of inducible cyclooxigenase and proinflamatory cytokines by sesquiterpene lactones in macrophages correlates with the inhibition of MAP kinases. Biochem Biophys Res Commun 226: 810-818.

44. Sepulveda-Boza S, Cassels BK (1996) Plan metabolites active against Trypanosoma cruzi. Planta Med 62: 98-115. 